\title{
Sistema público de Escrituração Digital: Percepção dos Gestores das Cooperativas Agropecuárias Catarinenses sobre os prováveis benefícios produzidos com sua implantação
}

\begin{abstract}
Mestrado em Ciências Contábeis pela Universidade Federal de Santa Catarina - UFSC Av. Aracaju, 225. Centro. Pinhalzinho/SC

E-mail:mb.carla@hotmail.com
\end{abstract}

Alex Fabiano Bertolo Santana Mestrado em Ciências Contábeis pela Universidade do Vale do Rio dos Sinos UNISINOS Av. Aracaju, 225, Centro. Pinhalzinho/SC E-mail: afbsantana@hotmail.com

César Augusto Lunkes Mestrado em Administração pela Universidade Federal de Santa Catarina - UFSC Av. Aracaju, 225, Centro. Pinhalzinho/SC E-mail: cesarlunkes2@hotmail.com

\section{RESUMO}

O Sistema Público de Escrituração Digital (SPED) representa uma nova fase da Contabilidade brasileira, apresentando-se como uma forma de modernização da escrituração e do cumprimento das exigências fiscais das empresas. O sistema é composto basicamente pela Escrituração Contábil Digital, Escrituração Fiscal Digital e pela Nota Fiscal Eletrônica, que tornam, respectivamente, digital o processo de escrituração e armazenamento dos livros contábeis e fiscais e eletrônicas a emissão da nota fiscal. A expectativa sobre o recente projeto, por parte do fisco, é que ele traga diversos benefícios, pois ele tende a reduzir o consumo de papel, a burocracia, o número de obrigações acessórias prestadas pelas empresas, dentre outros fatores, além de facilitar a fiscalização das administrações tributárias sobre as transações efetuadas pelo contribuinte, o que tende a diminuir a sonegação de tributos. Nesse sentido, nesta pesquisa de cunho bibliográfico e com caráter exploratório, fez-se uso da aplicação de questionário com perguntas fechadas, para identificar a percepção dos gestores de cooperativas agropecuárias de Santa Catarina sobre o projeto e seus benefícios. Foi possível concluir que apesar das dificuldades e custos iniciais identificados na pesquisa, os usuários acreditam que sua utilização será positiva e efetivamente trará os benefícios esperados.

Palavras-chave: Sistema Público de Escrituração Digital. Benefícios. Cooperativas. 
Sistema público de Escrituração Digital: Percepção dos Gestores das Cooperativas Agropecuárias Catarinenses sobre os prováveis benefícios produzidos com sua implantação Carla Maria Britz, Alex Fabiano Bertolo Santana, César Augusto Lunkes

\section{Public Digital Bookkeping System: Perception by the Managers of Agricultural Cooperatives from Santa Catarina about the possible benefits provided byits imaplantation}

\section{ABSTRACT}

Public Digital Bookkeeping System represents a new stage in Brazilian Accountancy, showing off as a new way of modernization of bookkeeping and the execution of the fiscal exigencies from the companies. It is composed basically of Digital Accounting Bookkeeping, Digital Fiscal Bookkeeping and by Electronic Receipt, that make, respectively, digital the process of bookkeeping and accountancy and fiscal books storage, and electronic, the emission of receipt. The expectation about the recent project, by the tax collection part, is that it will bring many benefits, as it tends to reduce paper consume, bureaucracy, among other factors, besides facilitating the supervision of tributary administration about the deals made by the taxpayer. In this way, this research was developed following a bibliographical methodology with an exploratory study and the application of a questionnaire with closed questions, to identify the perception by the agricultural cooperative managers from Santa Catarina about the project and its benefits, being possible to conclude that besides difficulties and the initial cost identified in the research, the users believe that its use will be positive and will effectively bring the expected benefits.

Keywords: Public Digital Bookkeeping System. Benefits. Cooperatives.

\section{INTRODUÇÃO}

A tecnologia vem facilitando as tarefas humanas, ela possibilita que se tenham controles, registros, cadastros e diversas outras ferramentas cada vez mais potentes a disposição. Hoje, praticamente todos os setores sociais e econômicos, tanto públicos quanto privados, se utilizam da agilidade, facilidade, melhoramento no controle e na qualidade das informações que esses meios oferecem.

O fisco utiliza da tecnologia principalmente para melhorar seu controle sobre as transações efetuadas pelas pessoas físicas e jurídicas, sendo que a mais nova medida nesse sentido foi a criação do Sistema Público de Escrituração Digital (SPED), aproximando os órgãos da administração tributária ao contribuinte, informatizando e agilizando os processos contábeis. Além disso, sua criação visa auxiliar o fisco a combater a sonegação de impostos e melhorar a qualidade da fiscalização. 
Sistema público de Escrituração Digital: Percepção dos Gestores das Cooperativas Agropecuárias Catarinenses sobre os prováveis benefícios produzidos com sua implantação Carla Maria Britz, Alex Fabiano Bertolo Santana, César Augusto Lunkes

A implantação do SPED irá exigir atualizações e adequações por parte dos profissionais contábeis e das empresas, pois é preciso conhecer as novas regras e procedimentos que deverão ser seguidos a partir de então, e ao mesmo tempo, adequar sistemas e equipamentos aos novos padrões estabelecidos. Inicialmente, o projeto será de uso obrigatório para certas empresas e setores estabelecidos na legislação e facultativo para os demais, devendo sua implantação ser incentivada progressivamente, até que atinja todas as empresas. Quanto aos seus efeitos, o fisco e os órgãos envolvidos acreditam que o SPED proporcionará vários benefícios, atingindo o fisco, as empresas e a sociedade como um todo.

O SPED é um projeto de iniciativa das três esferas do governo. Através dele os diferentes entes da federação poderão compartilhar as informações sobre os contribuintes, diminuindo a quantidade de obrigações acessórias que estes devem prestar. O SPED engloba basicamente a Escrituração Contábil Digital (ECD), a Escrituração Fiscal Digital (EFD) e a Nota Fiscal Eletrônica (NF-e).

A maioria das empresas já realiza sua Contabilidade com o auxílio de programas específicos, porém eram obrigadas a imprimir seus livros contábeis e armazená-los na forma de papel. Através do SPED será possível realizar e armazenar a escrituração contábil e fiscal de forma digital, sendo a validação desses arquivos realizada através da certificação digital, evitando que seja impresso desnecessariamente uma cópia daquilo que já estava armazenado no sistema, devido meramente a uma exigência legal, evitando gastos e prejuízos ambientais.

A NF-e irá informatizar o processo da emissão da nota fiscal, havendo uma troca de informações em tempo real entre o emitente e o fisco, gerando apenas uma via, diferentemente do antigo processo.

Esta é uma nova fase da Contabilidade, que é marcada principalmente pela substituição de documentos em papéis por documentos digitais, sendo que, para garantir a integridade e a validade jurídica dos documentos digitais será utilizada a certificação digital.

Considerando as mudanças que tendem a ocorrer na realização das atividades diárias das empresas, está pesquisa visa obter informações sobre os 
Sistema público de Escrituração Digital: Percepção dos Gestores das Cooperativas Agropecuárias Catarinenses sobre os prováveis benefícios produzidos com sua implantação Carla Maria Britz, Alex Fabiano Bertolo Santana, César Augusto Lunkes

custos, as dificuldades e os benefícios que as cooperativas que já utilizam o programa estão sentindo; verificar se os benefícios que a Receita Federal acredita que ele irá proporcionar estão se confirmando; além de identificar a percepção dos gestores de cooperativas agropecuárias catarinenses sobre o SPED.

\section{REFERENCIAL TEÓRICO}

\subsection{A Ciência Contábil}

Ludícibus e Marion (2007) afirmam que a Contabilidade é uma ciência social, pois é a ação humana que gera e modifica o fenômeno patrimonial. Todavia, a Contabilidade utiliza os métodos quantitativos (matemática e estatística) como sua principal ferramenta. Percebe-se, portanto, que a Contabilidade não é uma ciência exata, ela apenas faz uso das ferramentas fornecidas por ciências exatas para o seu desenvolvimento.

Existem diversos conceitos de contabilidade, porém todos remetem ao mesmo sentido, que é o uso desta ferramenta para a produção de informações que sejam úteis no gerenciamento das entidades. Para Marion (2004, p. 26), "a contabilidade é o instrumento que fornece o máximo de informações úteis para a tomada de decisões [...]. Com o passar do tempo, o governo começa a utilizar-se dela para arrecadar impostos e a torna obrigatória para a maioria das empresas".

Uma observação importante feita pelo autor no conceito recém citado, é o uso da contabilidade para a satisfação das exigências legais, pois hoje, devido ao complexo sistema tributário brasileiro e as diversas exigências fiscais existentes, essa tarefa toma um considerável tempo dos contadores, embora não seja essa a função nem o objeto da contabilidade.

\subsection{Um novo panorama na contabilidade brasileira}

A Contabilidade brasileira esta passando por profundas e significativas alterações, devido à adequação às normas internacionais, ao constante processo de informatização dos processos contábeis e às modificações que vem sendo realizadas na legislação tributária. Nesse processo de informatização e alterações 
Sistema público de Escrituração Digital: Percepção dos Gestores das Cooperativas Agropecuárias Catarinenses sobre os prováveis benefícios produzidos com sua implantação Carla Maria Britz, Alex Fabiano Bertolo Santana, César Augusto Lunkes

legais, principalmente no contexto fiscal, surge o Sistema Público de Escrituração Digital (SPED), que merece destaque pela modernização e mudanças que trará aos processos contábeis. Portanto, estão ocorrendo simultaneamente dois processos que tendem a causar grandes impactos aos profissionais contábeis e às empresas.

Segundo Resende (2008, p.21), “... o sistema contábil brasileiro passa por uma transformação nunca vista na história. Além das mudanças das regras contábeis para a convergência aos padrões internacionais, as empresas precisam se adequar à entrada do Sistema Público de Escrituração Digital (SPED) ".

Inicialmente, até que todos estejam bem adaptados, a implantação do SPED exigirá estudo dos profissionais contábeis para que conheçam sua sistemática de funcionamento e a legislação aplicável. Porém, a tendência é que quando o SPED estiver em pleno funcionamento, ele venha a diminuir o tempo que o contador despende com a área tributária das empresas, pois ele tende a reduzir as obrigações acessórias, agilizar os processos, ou seja, diminuir o trabalho fiscal do contador, caracterizando mais uma importante alteração que o programa proporcionará.

\subsubsection{Sistema Público de Escrituração Digital (SPED)}

O SPED foi instituído pelo Decreto $n^{\circ}$ 6.022, de 22 de janeiro de 2007, sendo parte do Programa de Aceleração do Crescimento (PAC), segundo a Receita Federal (2009).

$O$ artigo $2^{\circ}$, do Decreto $n^{\circ} 6.022$ define o SPED como sendo um "instrumento que unifica as atividades de recepção, validação, armazenamento e autenticação de livros e documentos que integram a escrituração comercial e fiscal dos empresários e das sociedades empresárias, mediante fluxo único, computadorizado, de informações".

A unificação mencionada na definição do SPED representa que o contribuinte vai prestar as informações uma única vez, pois o SPED possibilitará o compartilhamento das informações fiscais entre as administrações tributárias. Como complemento ao comentado cabe ressaltar que 0 artigo $4^{\circ}$ do mencionado Decreto expõe que as informações do SPED deverão ser compartilhadas entre seus usuários, no âmbito de sua competência, sem deixar de observar o sigilo bancário comercial e fiscal, e que as 
Sistema público de Escrituração Digital: Percepção dos Gestores das Cooperativas Agropecuárias Catarinenses sobre os prováveis benefícios produzidos com sua implantação Carla Maria Britz, Alex Fabiano Bertolo Santana, César Augusto Lunkes

sociedades empresarias e os empresários terão acesso às informações por eles fornecidas ao SPED.

O SPED está modernizando os processos de emissão da nota fiscal e de escrituração fiscal e contábil das empresas, além de estar tornando comum no dia-a-dia destas o uso de documentos eletrônicos e da certificação digital. Os parágrafos $1^{\circ}$ e $2^{\circ}$ do artigo $2^{\circ}$ do Decreto 6.022, reafirmam esta situação, estabelecendo que os livros e documentos fiscais sejam emitidos sob a forma eletrônica, observando os critérios de certificação digital da Infra-Estrutura de Chaves Públicas Brasileira (ICP-Brasil), que irá assegurar a autenticidade, a integridade e a validade jurídica das informações contidas nos documentos eletrônicos.

\subsubsection{Escrituração Contábil Digital}

A Escrituração Contábil Digital (ECD), conhecida também como SPED Contábil, foi instituída pela Instrução Normativa da Receita Federal do Brasil n 787 de 19 de dezembro de 2007. Consiste basicamente na substituição dos livros contábeis em papéis por arquivos na forma digital. A Receita Federal (2009) define " o SPED Contábil como a substituição dos livros da escrituração mercantil pelos seus equivalentes digitais".

A Instrução Normativa $n^{\circ} 787$, estabelece em seu artigo $3^{\circ}$, a obrigatoriedade de realização da ECD, afirmando que estão obrigados a sua utilização:

- Sobre os fatos contábeis ocorridos a partir de $1^{\circ}$ de janeiro de 2008 , as sociedades empresarias tributadas pelo lucro real e sujeitas a acompanhamento econômico-tributário diferenciado; e

- Sobre os fatos contábeis ocorridos a partir de $1^{\circ}$ de janeiro de 2009 as demais empresas tributadas pelo lucro real.

Para as demais pessoas jurídicas sua realização é facultativa, porém ela tende a ser utilizada por todas as empresas brasileiras futuramente, é apenas uma questão de tempo e adaptações. 
Sistema público de Escrituração Digital: Percepção dos Gestores das Cooperativas Agropecuárias Catarinenses sobre os prováveis benefícios produzidos com sua implantação Carla Maria Britz, Alex Fabiano Bertolo Santana, César Augusto Lunkes

\subsubsection{Escrituração Fiscal Digital}

A Escrituração Fiscal Digital (EFD), conhecida também como SPED Fiscal, foi instituída pelo Convênio ICMS no 143 de 15 de dezembro de 2006, consistindo em um arquivo digital da escrituração fiscal das empresas.

O Convênio ICMS $n^{\circ} 143$, em sua cláusula primeira, define a EFD como um arquivo digital, que se constitui em um "conjunto de escrituração de documentos fiscais e de outras informações de interesse dos fiscos das unidades federadas e da Secretaria da Receita Federal".

Portanto, a EFD é em um arquivo digital que contém as informações que devem ser repassadas pelo contribuinte ao fisco, para que este possa realizar a fiscalização do cumprimento das obrigações fiscais das empresas.

Quanto a sua obrigatoriedade, a Receita Federal divulga a lista dos obrigados, observando que as empresas do SIMPLES (Sistema Integrado de Pagamento de Imposto e Contribuições das Microempresas e Empresas de Pequeno Porte) estão excluídas desta.

\subsubsection{Nota Fiscal Eletrônica}

O projeto da NF-e está sendo desenvolvido de forma integrada pela Receita Federal do Brasil, Estados, Distrito federal, e municípios, de acordo com o Protocolo de Cooperação ENAT $n^{\circ} 3$, de 27 de agosto de 2005, que objetiva a sua implantação.

O desenvolvimento e o uso da NF-e representam uma evolução, pois sua implantação está informatizando um dos processos mais usuais e comuns da Contabilidade diária das empresas, a emissão do documento fiscal que registra suas operações, a nota fiscal.

O Ajuste SINIEF $n^{\circ} 7$, de 2005, conceitua a NF-e em sua cláusula primeira, afirmando que ela é "o documento emitido e armazenado eletronicamente, de existência apenas digital, com o intuito de documentar operações e prestações". Portanto, a nota fiscal passa a existir apenas na forma digital, não havendo mais a existência física do documento, observando que será impresso apenas o Documento 
Sistema público de Escrituração Digital: Percepção dos Gestores das Cooperativas Agropecuárias Catarinenses sobre os prováveis benefícios produzidos com sua implantação Carla Maria Britz, Alex Fabiano Bertolo Santana, César Augusto Lunkes

Auxiliar da NF-e, conhecido por DANFE, que representa a NF-e e irá acompanhar a mercadoria. Sua emissão se dará antes da ocorrência do fato gerador, ou seja, da saída da mercadoria do estabelecimento do contribuinte, sendo a validade jurídica do documento assegurada pela assinatura digital do emitente e pela referida autorização de uso que será emitida pelo fisco.

Conforme dados do Portal da NF-e, a obrigatoriedade de sua utilização é apresentada na legislação, sendo esta estabelecida por ramos de atividade, observando que o número de ramos abrangidos pelo uso da NF-e vem sendo aumentados progressivamente através de alterações na legislação vigente, contemplando a cada alteração um maior número de setores.

\subsubsection{Benefícios produzidos pelo SPED}

A expectativa quanto aos efeitos que a implantação do SPED trará, é positiva. A Receita Federal (2009), uma das idealizadoras do projeto e a responsável por sua administração, acredita que o SPED trará vários benefícios, estando eles descritos no Sitio do SPED. Dentre eles estão a redução de custos com a dispensa de emissão e armazenamento de documentos em papel, a racionalização e simplificação das obrigações acessórias, a uniformização das informações que o contribuinte presta as diversas unidades federadas, o fortalecimento do controle e da fiscalização por meio de intercâmbio de informações entre as administrações tributárias, a redução do custo Brasil, o aperfeiçoamento do combate à sonegação e a preservação do meio ambiente pela redução do consumo de papel.

O SPED irá melhorar a qualidade das informações prestadas pelas empresas, permitindo aos fiscos das diferentes unidades federadas que compartilhem essas informações, realizar o cruzamento dos dados contábeis e fiscais prestados pelos contribuintes, facilitando a descoberta de prováveis irregularidades.

Outra importante contribuição que o SPED deve proporcionar é a redução do custo Brasil, que tende a se efetivar, devido ao custo das empresas com burocracia, papéis e exigências fiscais ser diminuído com a completa implantação do SPED, o que trará efeitos para toda a sociedade, pois o custo do processo produtivo irá diminuir. 
Sistema público de Escrituração Digital: Percepção dos Gestores das Cooperativas Agropecuárias Catarinenses sobre os prováveis benefícios produzidos com sua implantação Carla Maria Britz, Alex Fabiano Bertolo Santana, César Augusto Lunkes

Resende (2008, p. 23) acredita que "O SPED é um passo positivo, assim como a Nota Fiscal Eletrônica. Essa mudança vai permitir o barateamento da prestação de contas, após a implantação, mas pode exigir, em algumas hipóteses, elevado investimento".

Cabe observar que, uma vez implementado o SPED, este tende a trazer economia para as empresas, embora sua implantação, em alguns casos, pode ter um custo considerável. Ele exige a modernização das empresas, sendo que para aquelas que já fazem uso de um bom aparato de hardware e software, ele não representa grandes investimentos, mas para as que não os possuem, ou que possuem equipamentos com limitações, sua implantação pode ter um custo relevante.

\section{METODOLOGIA}

Este estudo caracteriza-se por ser uma pesquisa bibliográfica-exploratória, tendo o problema caráter qualitativo e quantitativo aplicado, pois compreende a realização de pesquisa em referenciais teóricos sobre o SPED, um assunto novo e pouco explorado, e uma pesquisa de campo em cooperativas agropecuárias catarinenses, utilizando-se de métodos estatísticos para a análise e interpretação dos dados obtidos através da aplicação de questionário.

O universo de estudo da pesquisa compreende as cooperativas de Santa Catarina listadas na Organização das Cooperativas do Estado de Santa Catarina (OCESC), sendo a amostra constituída pelas cooperativas agropecuárias do estado listadas no referido órgão, ramo escolhido devido a grande representatividade no estado.

O questionário foi enviado para o endereço eletrônico de todas as cooperativas agropecuárias catarinenses, que são atualmente 50 cooperativas, de acordo com a listagem encontrada no site da OCESC, observando que para as conclusões obtidas serem consideradas válidas e confiáveis foi estabelecido como o limite mínimo de retorno oito questionários, de acordo com o nível de inspeção II da NBR 5426. 
Sistema público de Escrituração Digital: Percepção dos Gestores das Cooperativas Agropecuárias Catarinenses sobre os prováveis benefícios produzidos com sua implantação Carla Maria Britz, Alex Fabiano Bertolo Santana, César Augusto Lunkes

Para alcançar os objetivos desta pesquisa, o questionário contemplou questões específicas para as cooperativas que já trabalham com o SPED, buscando identificar as dificuldades e os custos que estas tiveram para sua implantação e se houveram benefícios. Também contemplou questões para os usuários e não usuários do programa, verificando a percepção de ambos sobre o projeto e sobre os benefícios que o governo promete que ele trará.

\section{APRESENTAÇÃO E ANÁLISE DOS RESULTADOS}

Dos questionários enviados para as cinquenta cooperativas que constituem o objeto de estudo da pesquisa, doze retornaram respondidos, atingindo um índice de retorno de $24 \%$ do total.

Os questionários foram respondidos em três áreas dentro das cooperativas, sendo elas a administração, contabilidade e controladoria. Observando que a pesquisa visava conhecer a percepção dos gestores, os respondentes estão dentro dos parâmetros desejados, pois ambas as áreas estão ligadas diretamente com a gestão das cooperativas. A proporção de questionários respondidos indica que $58 \%$ foram respondidos na contabilidade, $25 \%$ na administração e $17 \%$ na controladoria das cooperativas. Percebe-se claramente que a área em que mais questionários foram respondidos é a contabilidade, algo facilmente explicável devido à relação do SPED com o trabalho do contador.

\subsection{Adesão ao SPED}

Através do questionamento sobre a utilização do SPED foi possível identificar o nível de adesão das cooperativas agropecuárias do estado de Santa Catarina amostradas ao projeto do fisco; se essa adesão foi voluntária ou obrigatória, além de possibilitar a segregação do grupo entre usuários e não-usuários do SPED, para a realização de perguntas especificas aos usuários do mesmo.

Das cooperativas analisadas, a maioria já faz uso do SPED, sendo que $17 \%$ estão implantando e $66 \%$ já possuem o programa implantado, o que dá um total de 
Sistema público de Escrituração Digital: Percepção dos Gestores das Cooperativas Agropecuárias Catarinenses sobre os prováveis benefícios produzidos com sua implantação Carla Maria Britz, Alex Fabiano Bertolo Santana, César Augusto Lunkes

83\% de adesão, enquanto que apenas 17\% ainda não aderiram ao seu uso (Gráfico 1).

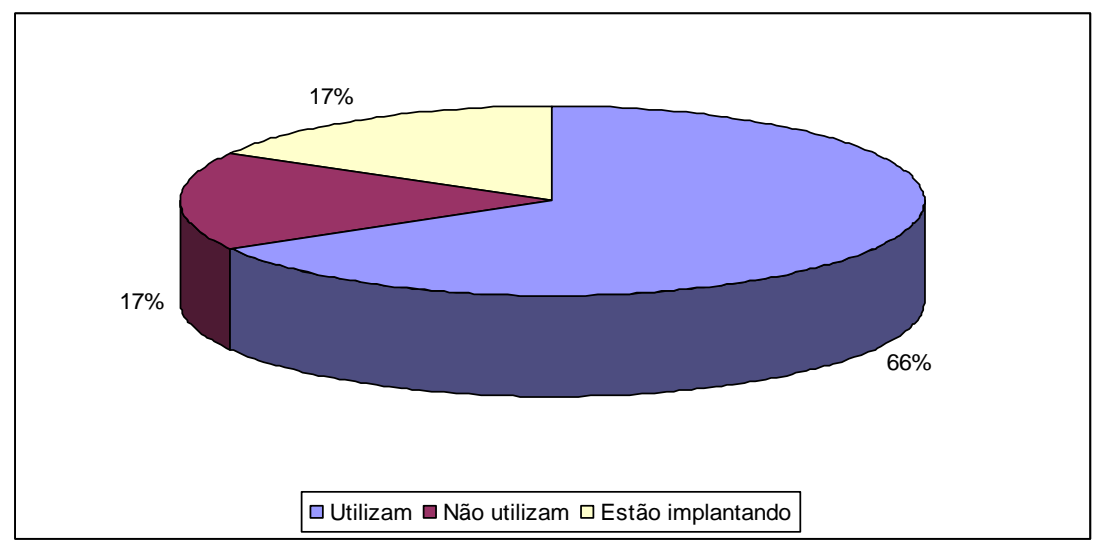

Gráfico 1 - Adesão das Cooperativas ao SPED

Fonte: Dados da pesquisa

Os 17\% que não utilizam o SPED, em números, representam duas cooperativas, sendo possível perceber que a adesão ao uso do SPED nas cooperativas agropecuárias do estado de Santa Catarina é bastante representativa.

Quanto ao fato dessa adesão ter sido voluntária ou imposta pela legislação a estas cooperativas, considerando que as obrigatoriedades dos componentes do SPED são diferenciadas, foi possível observar que das cooperativas que utilizam o SPED todas elas, segundo observações feitas no questionário, estão obrigadas a utilização de pelo menos um dos componentes do SPED e aderiram, ou estão aderindo voluntariamente aos demais. Isso que leva a concluir que foi a obrigação a um dos componentes que fez as cooperativas aderirem ao uso do SPED, mas em contrapartida estão aderindo livremente ao total do projeto.

\subsection{Cooperativas que utilizam o SPED}

A partir da obtenção da resposta sobre a adesão ao SPED a pesquisa é direcionada especificamente as dez cooperativas que o utilizam, visando conhecer os reais efeitos deste na realidade das cooperativas. 


\subsubsection{Custos de implantação do SPED}

Procurou-se identificar se as cooperativas realmente tiveram custos para implantar o programa, e se estes foram altos ou baixos. Os resultados obtidos revelam que todas as cooperativas tiveram custos adicionais para implantar o SPED, sendo que para $60 \%$ das cooperativas analisadas estes custos foram baixos e para $40 \%$ foram altos.

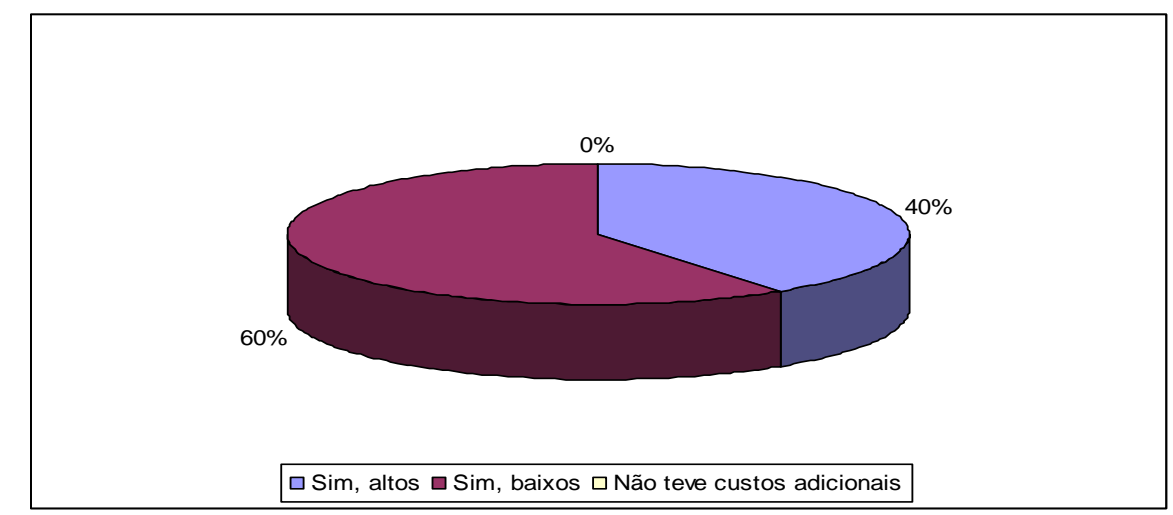

Gráfico 2 - Cooperativas que tiveram custos adicionais para implantar o SPED Fonte: Dados da pesquisa

Percebe-se que custos todos tiveram, no entanto na grande maioria esses custos foram baixos, o que é positivo. Posteriormente, identificaram-se quais foram esses custos de implantação, sendo possível observar que estes compreendem basicamente equipamentos e infra-estrutura física, adequação do sistema contábil e treinamento de pessoal, nas seguintes proporções: 


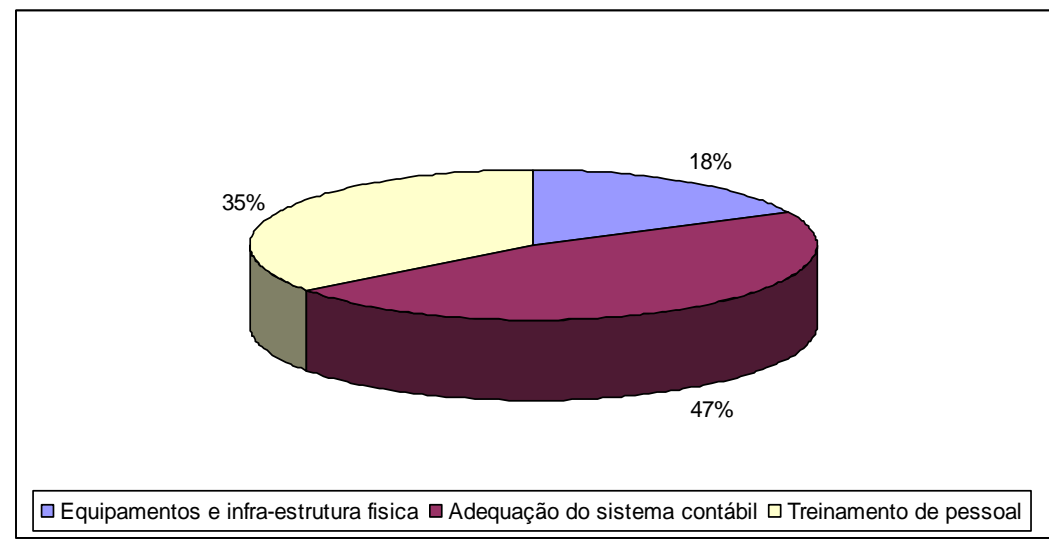

Gráfico 3 - Identificação dos custos

Fonte: Dados da pesquisa

Algumas cooperativas tiveram apenas um ou dois dos custos citados, não apresentando todos, enquanto que outras apresentaram todos esses fatores como custos adicionais com a implantação do SPED.

Unindo todas essas informações, conclui-se que, em geral, o custo mais representativo é a adequação do sistema contábil das mesmas, que terá de estar dentro dos padrões exigidos na legislação do SPED e possuir os aplicativos necessários para a efetiva realização da escrituração fiscal e contábil digital e emissão da nota fiscal eletrônica. Este custo é seguido da adaptação dos equipamentos físicos que deverão comportar as funcionalidades do sistema e, posteriormente, pelo treinamento de seus colaboradores, para possibilitar um maior entendimento sobre a legislação e funcionamento da nova sistemática usada a partir de então.

\subsubsection{Principais dificuldades encontradas}

A implantação do SPED trouxe certas dificuldades para as cooperativas, algo facilmente compreensível, considerando tratar-se de um projeto novo, que exige adequações que envolvem custos, aprendizado e mudança na rotina das mesmas. As dificuldades identificadas nas cooperativas estão representadas no gráfico 4. 


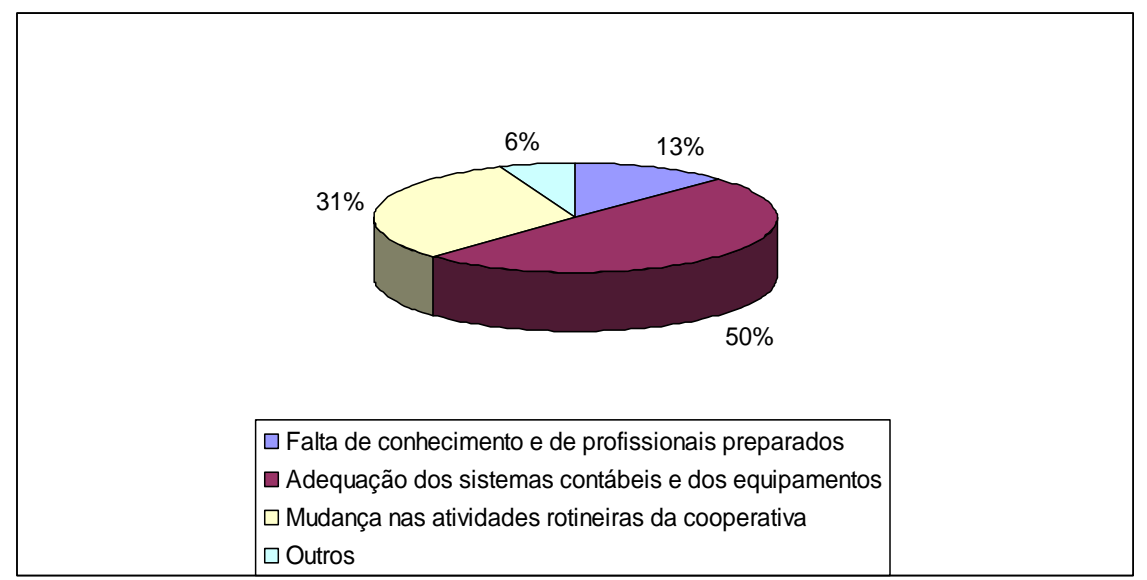

Gráfico 4 - Maiores dificuldades identificadas Fonte: Dados da pesquisa

Percebe-se como maior dificuldade das cooperativas, com um índice bastante representativo de $50 \%$, à adequação dos sistemas contábeis e da infra-estrutura física, justamente os itens que envolvem o maior custo, de acordo com a análise anterior, levando a concluir que a maior dificuldade das cooperativas está na questão dos gastos adicionais que a implantação do SPED trouxe no seu orçamento.

A segunda maior dificuldade encontrada, representando $31 \%$, foi a mudança que ocorreu no modo de realização das atividades rotineiras da empresa, sendo perceptível nesse ponto a questão da dificuldade encontrada quando se altera algo que sempre foi realizado de um mesmo modo. Na sequência vem a dificuldade da falta de conhecimento e de pessoas que dominem bem o funcionamento e as peculiaridades do SPED, pois, trata-se de algo novo e faltam pessoas que possuam um bom entendimento sobre o mesmo, algo que de certa forma pode ser considerado até natural por enquanto, considerando a juventude do programa.

Apenas uma cooperativa apresentou outra dificuldade, além das mencionadas, afirmando que "problemas nos sistemas disponibilizados pelo fisco, traziam a cada semana mudanças que prejudicaram e muito o trabalho". Este é um ponto importante, pois de acordo com o respondente, inicialmente, nem o próprio fisco, um dos idealizadores do projeto, estava bem estruturado em relação ao projeto, o que com certeza dificultou as coisas para as empresas. 
Sistema público de Escrituração Digital: Percepção dos Gestores das Cooperativas Agropecuárias Catarinenses sobre os prováveis benefícios produzidos com sua implantação Carla Maria Britz, Alex Fabiano Bertolo Santana, César Augusto Lunkes

\subsubsection{Benefícios com a utilização do SPED}

A Receita Federal e os demais idealizadores do SPED apresentam uma série de benefícios que este projeto deverá proporcionar através de sua utilização. As cooperativas analisadas quando questionadas com relação aos benefícios que o SPED Ihes trouxe neste período de utilização, apresentaram as respostas representadas abaixo.

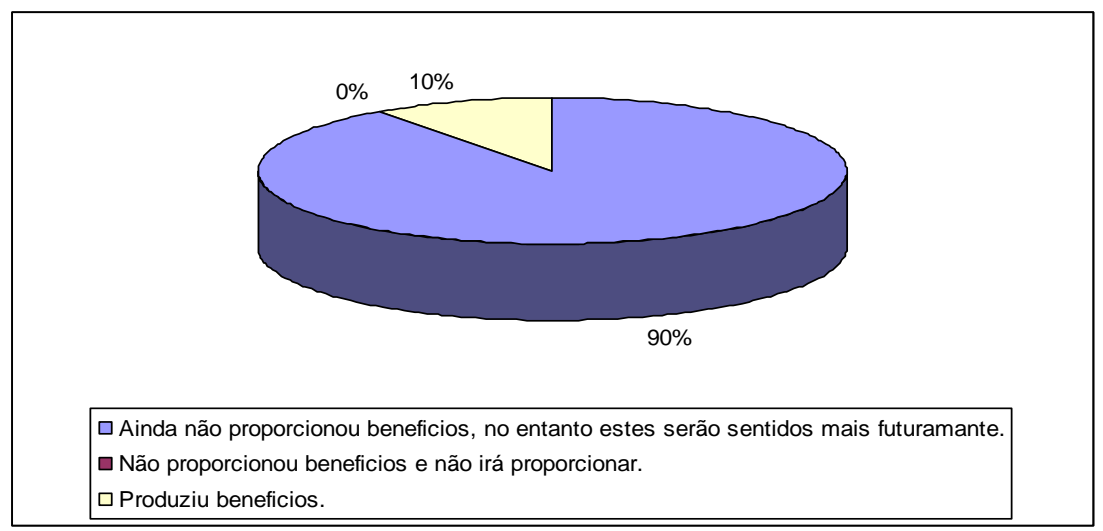

Gráfico 5 - Benefícios do SPED

Fonte: Dados da pesquisa

A grande maioria das cooperativas (90\%) afirmam que o SPED ainda não thes proporcionou benefícios, no entanto, acreditam que esses benefícios serão sentidos futuramente, pois este é um projeto recente e ainda não surtiu os efeitos esperados, revelando uma expectativa positiva com relação aos resultados que o SPED deverá proporcionar.

Um dos respondentes das cooperativas pesquisadas observou o seguinte: "Para as empresas que trabalham totalmente legalizadas será mais positivo ainda, pois atualmente existe muita sonegação, o que muitas vezes inviabiliza o nosso negócio, pois temos uma competitividade desleal, e através do SPED, seja o Contábil, Fiscal ou Nota Fiscal Eletrônica, isso vai acabar; todos terão a mesma carga tributária".

Isso revela a expectativa sobre um beneficio que tende a ser proporcionado, pois o SPED vai reduzir a sonegação de impostos, o que vai deixar as empresas em situação de igualdade, não permitindo mais que algumas se beneficiem ilegalmente através da sonegação. 
Sistema público de Escrituração Digital: Percepção dos Gestores das Cooperativas Agropecuárias Catarinenses sobre os prováveis benefícios produzidos com sua implantação Carla Maria Britz, Alex Fabiano Bertolo Santana, César Augusto Lunkes

Dos pesquisados, $10 \%$ afirmam já estarem sendo beneficiados através da economia de papel. Observa-se que um dado relevante é o fato de nenhum respondente ter afirmado que o SPED não proporcionou e não irá proporcionar benefícios. Esse fato, juntamente com as demais respostas, onde todos acreditam nos resultados positivos do programa, revela que o projeto é visto com bons olhos pelos gestores das cooperativas agropecuárias de Santa Catarina que compõem a amostra do estudo.

\subsubsection{Benefícios esperados versus Benefícios proporcionados}

A Receita Federal expõe diversos benefícios que devem ser proporcionados com a implantação do SPED. Um dos objetivos desta pesquisa é identificar se estes estão de fato se confirmando na realidade das pesquisadas, sendo que através da análise das respostas obtidas sobre os benefícios, realizada no item anterior, foi possível concluir que, por enquanto, o único beneficio que já se confirmou foi a economia no consumo de papel, porém todos acreditam que os benefícios virão. $O$ fato é que talvez a implantação do SPED nessas cooperativas ainda seja muito recente para realizar essa análise, pois elas próprias, em sua maioria, ainda não tiveram esse retorno, mas acreditam que ele virá.

\subsection{Percepção dos Gestores das Cooperativas sobre o SPED}

Nesse momento, a análise volta a ser direcionada a todos os respondentes, compreendendo usuários e não usuários do SPED, com o intuito de identificar a percepção dos gestores de cooperativas agropecuárias de Santa Catarina sobre o SPED.

Em relação à opinião dos gestores sobre o SPED como um todo, $67 \%$ acreditam que ele é bom para as empresas e para o fisco, enquanto que $33 \%$ acreditam que ele é bom apenas para o fisco, e ninguém considerou que ele é positivo somente para as empresas ou que não é um bom projeto. 
Sistema público de Escrituração Digital: Percepção dos Gestores das Cooperativas Agropecuárias Catarinenses sobre os prováveis benefícios produzidos com sua implantação Carla Maria Britz, Alex Fabiano Bertolo Santana, César Augusto Lunkes

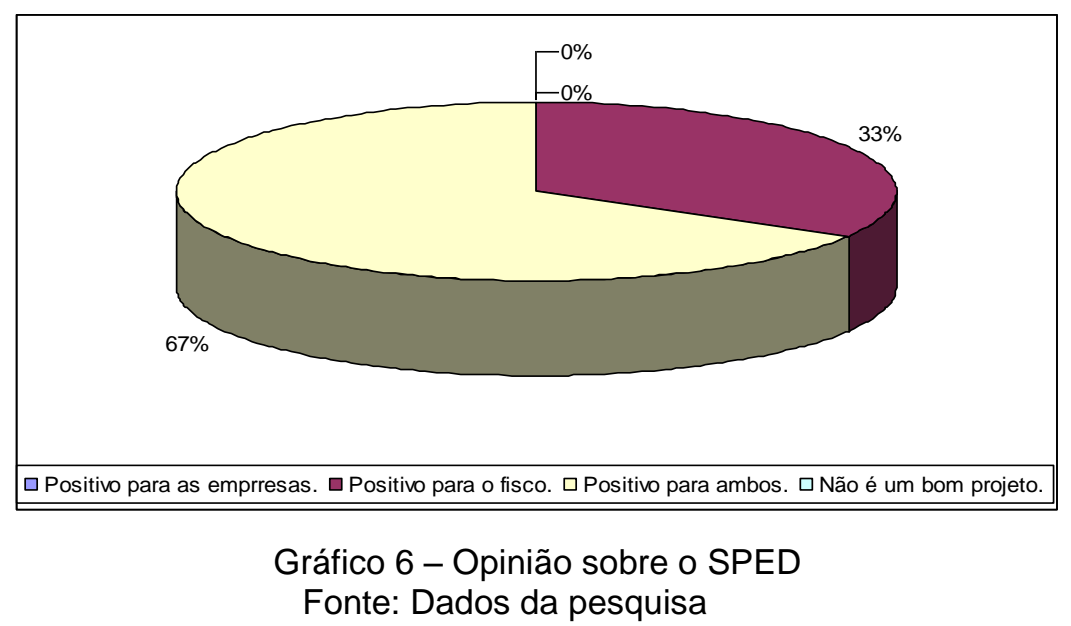

É possível perceber que a idéia de que o SPED favorece o fisco está bem presente na resposta, pois apesar de a maioria ter considerado ele favorável às empresas e ao fisco, todos o acharam favorável ao fisco e ninguém o achou favorável apenas às empresas.

\subsubsection{Percepção sobre os benefícios do SPED}

Apresentadas as opiniões sobre o projeto como um todo, parte-se agora para uma análise específica da opinião dos pesquisados sobre os prováveis benefícios que a implantação do SPED produz. Para tanto, foram realizadas afirmações, com base nos benefícios que a Receita Federal acredita que o SPED traz, e oferecidas pesquisadas opções de concordância e discordância total ou parcial.

Em relação ao benefício da redução de custos, através da economia no consumo de papel, o que leva também a um benefício social, pois preserva o meio ambiente, os pesquisados responderam o seguinte: 
Sistema público de Escrituração Digital: Percepção dos Gestores das Cooperativas Agropecuárias Catarinenses sobre os prováveis benefícios produzidos com sua implantação

Carla Maria Britz, Alex Fabiano Bertolo Santana, César Augusto Lunkes

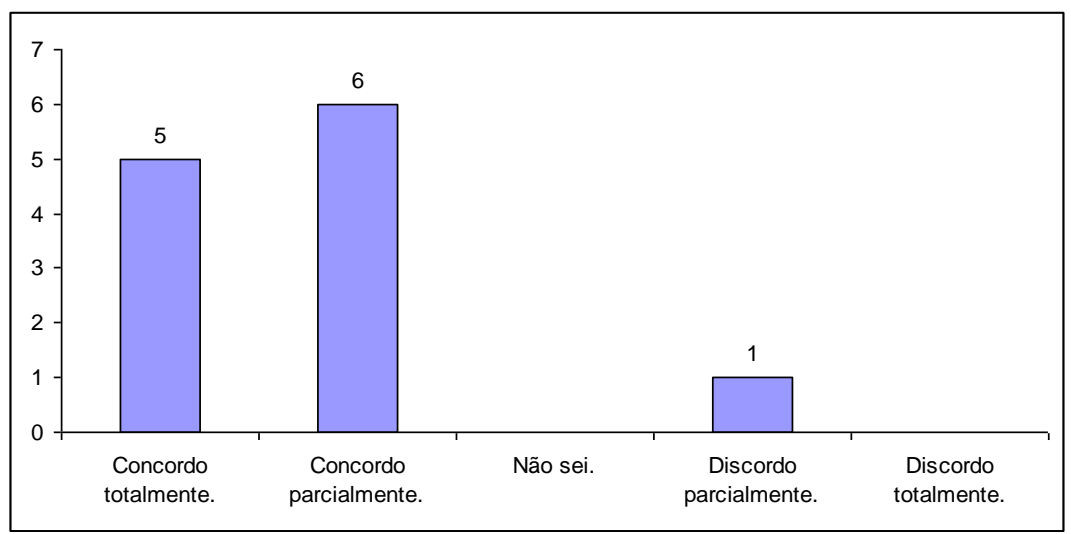

Gráfico 7 - O SPED reduz o consumo e os custos com papel Fonte: Dados da pesquisa

Conforme os dados expostos na tabela, cinco respondentes, que correspondem a $42 \%$ do total, concordaram totalmente com a afirmação, $50 \%$ parcialmente e uma cooperativa, que corresponde a $8 \%$, discorda parcialmente. Percebe-se a predominância da concordância com 0 item exposto, havendo apenas uma discordância, que ainda é parcial.

Foi afirmado que o SPED reduz a quantidade de obrigações acessórias que devem ser prestadas pelas empresas, pois ele uniformiza as informações prestadas para as diferentes unidades federadas. As posições dos respondentes estão apresentadas no gráfico 8 . 


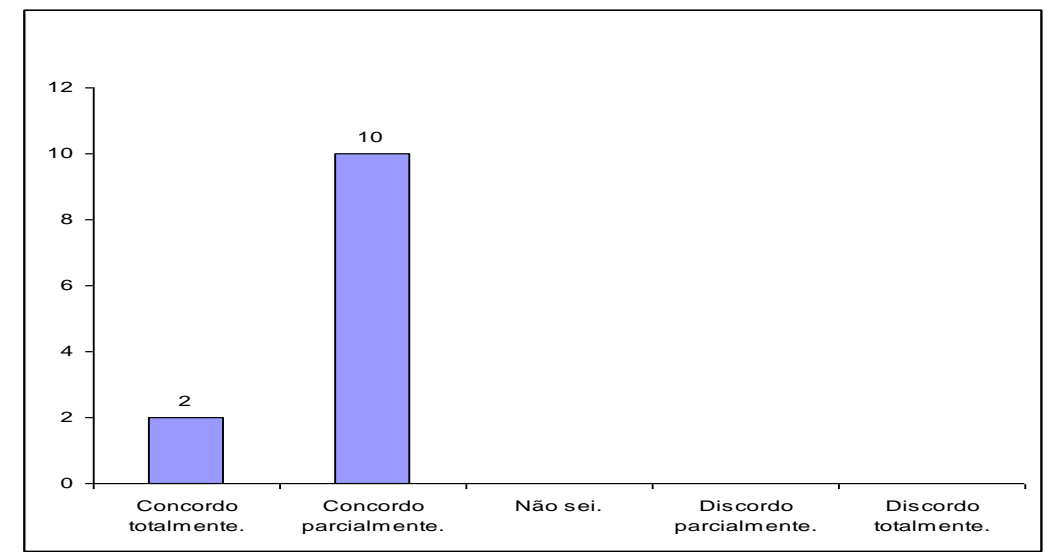

Gráfico 8 - O SPED reduz o número de obrigações acessórias a serem prestadas

Fonte: Dados da pesquisa

Observa-se que nenhum respondente discordou deste item, sendo que $17 \%$, que equivalem a duas cooperativas, concordam totalmente, e $83 \%$, equivalente a dez cooperativas, parcialmente, o que revela um alto índice de concordância parcial. Pelo exposto, os respondentes acreditam que, de certa forma, o SPED trará esse beneficio aos seus usuários.

Outro benefício que a receita afirma que o SPED trará é a redução da burocracia e a agilidade na realização das tarefas. Com relação a essa afirmação, 17\% dos respondentes concordaram totalmente, $58 \%$ parcialmente, enquanto que $17 \%$ discordaram parcialmente e $8 \%$ totalmente. Embora a maioria tenha concordado, percebe-se um índice maior de discordância do que nas afirmações anteriores, acredito que isso se deva ao fato de inicialmente o SPED causar mais transtornos do que agilidade, até que sejam feitas as adequações necessárias e tudo esteja funcionando conforme deve.

O SPED também tende a ser uma importante ferramenta no combate a sonegação de impostos. A concordância foi unânime entre os respondentes, sendo que $92 \%$ concordaram totalmente e $8 \%$ parcialmente. 


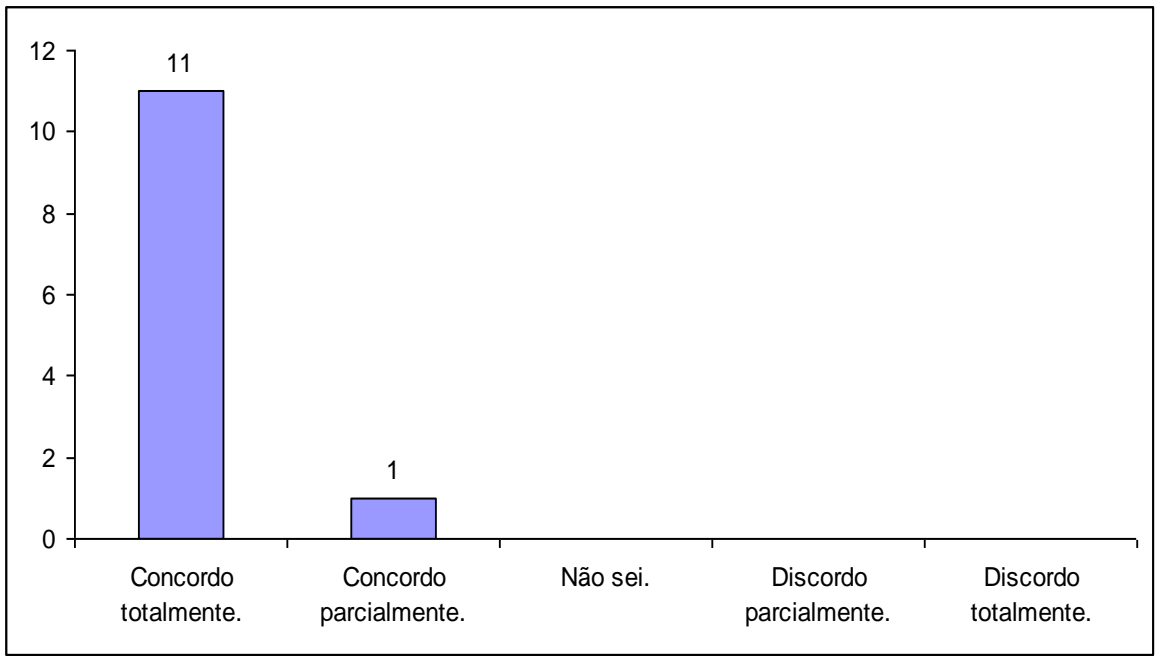

Gráfico 9 - O SPED é uma importante ferramenta no combate a sonegação de impostos Fonte: Dados da pesquisa

Isso revela, que apesar de os pesquisados acreditarem, de acordo com os itens anteriores, que o SPED produz benefícios para as empresas, há uma forte predominância na idéia de o mesmo ser usado principalmente no combate a sonegação, a serviço do fisco, tanto que esta é a única questão em que ocorre unanimidade de concordância, mostrando que de fato todos acreditam que o SPED é principalmente um instrumento de uso do fisco para melhorar seu controle sobre as transações efetuadas pelas empresas, como também já havia sido concluído anteriormente no item referente a opinião sobre o projeto. Lembrando, porém, que isso também será muito bom para as empresas que não sonegam, pois irá diminuir a concorrência desleal entre aqueles que cumprem com suas obrigações fiscais e aqueles que sonegam impostos em benefício próprio, deixando todos em situação de igualdade.

\section{CONCLUSÃO}

O SPED se apresenta como uma nova sistemática de realização e armazenamento das informações contábeis e fiscais das empresas, compreendendo basicamente a substituição da nota fiscal e da escrituração contábil e fiscal das empresas em papel, por arquivos digitais equivalentes, a NF-e e o SPED contábil e 
Sistema público de Escrituração Digital: Percepção dos Gestores das Cooperativas Agropecuárias Catarinenses sobre os prováveis benefícios produzidos com sua implantação Carla Maria Britz, Alex Fabiano Bertolo Santana, César Augusto Lunkes

fiscal, respectivamente, que terão sua autenticidade e validade jurídica garantida pela certificação digital, de acordo com os padrões da ICP-Brasil. Sendo um instrumento que irá permitir o compartilhamento das informações prestadas pelas pessoas jurídicas entre os diferentes entes federados.

Os objetivos desta pesquisa consistiam basicamente em identificar a percepção dos gestores de cooperativas agropecuárias de Santa Catarina sobre o SPED e seus benefícios e verificar os reais efeitos deste na realidade das cooperativas que já aderiram ao projeto, identificando custos, dificuldades e benefícios.

Nas cooperativas agropecuárias de Santa Catarina analisadas, a adesão ao SPED é bastante representativa, sendo que, em uma análise geral, percebe-se que a aceitação do programa e seus efeitos no dia-a-dia destas vem sendo razoável, tendendo para o positivo, apesar de ser possível perceber dificuldades iniciais, devido a transtornos com adequações por parte das empresas e por problemas no próprio sistema do fisco.

Analisando as cooperativas que utilizam o SPED, verificou-se que o processo de implantação gerou custos adicionais para todas, sendo estes, porém, baixos, para a maioria destas, compreendendo gastos com treinamento de funcionários, infra-estrutura física e a adequação de seus sistemas contábeis aos novos padrões e procedimentos que devem ser seguidos a partir de então, sendo o último, o custo mais representativo para estas.

As dificuldades de implantação do SPED compreendem a falta de conhecimento sobre o projeto, a mudança no modo de realização das tarefas rotineiras e, citada como a maior dificuldade encontrada pelas cooperativas, a adequação dos sistemas e da parte física a nova sistemática, que de acordo com as mesmas foi o processo responsável pela geração de maiores custos de implantação. Isso revela que a maior dificuldade das cooperativas está justamente nos custos de implantação do programa.

Quanto aos benefícios que a Receita Federal e os demais idealizadores do SPED mencionam que deverão ser sentidos com a sua utilização, a grande maioria das cooperativas usuárias do SPED consideram que o mesmo ainda não produziu 
Sistema público de Escrituração Digital: Percepção dos Gestores das Cooperativas Agropecuárias Catarinenses sobre os prováveis benefícios produzidos com sua implantação Carla Maria Britz, Alex Fabiano Bertolo Santana, César Augusto Lunkes

benefícios devido ao fato de sua utilização ser recente e ainda não ter gerado os efeitos esperados, porém todas acreditam que estes virão futuramente.

Portanto, ainda não é possível definir se os benefícios mencionados pela Receita Federal estão se confirmando na realidade, devido ao pouco tempo de utilização do SPED nas cooperativas analisadas, pois elas próprias ainda não possuem noção exata dos resultados até então, ficando aqui uma oportunidade para a realização de novas pesquisas sobre o assunto. Porém, percebe-se, com os dados já obtidos, que as cooperativas usuárias do SPED apesar dos custos e dificuldades iniciais possuem uma expectativa positiva a respeito dos benefícios que o projeto proporcionará para elas, citando inclusive a diminuição da concorrência desleal, que será possível através do controle da sonegação de impostos pelo fisco, um dos benefícios do projeto.

As cooperativas analisadas, usuárias e não usuárias do SPED acreditam, em sua maioria, que o mesmo reduzirá efetivamente o consumo de papel, a quantidade de obrigações acessórias, a burocracia, e irá proporcionar agilidade na realização das tarefas e contribuir primordialmente para o controle da sonegação de impostos. Isso revela que estas cooperativas acreditam que os benefícios elencados pela Receita Federal vão de fato se efetivar na realidade das empresas, sendo possível observar, porém, uma visão predominante de que o projeto vai ser extremamente útil para o fisco, ou seja, as cooperativas consideram o projeto bom para as empresas, mas principalmente para o fisco, pois através do SPED o mesmo vai aprimorar a fiscalização, o que consequentemente vai aumentar sua arrecadação.

Conclui-se, de forma geral, que custos e dificuldades de implantação existem, entretanto, a aceitação e a visão geral, tanto entre usuários e não-usuários do SPED é boa, e a expectativa sobre os benefícios que este deve proporcionar é positiva.

\section{REFERÊNCIAS}

BRASÍLIA. Decreto $n^{\circ}$ 6.022, de 22 de janeiro de 2007. Institui o Sistema Público de Escrituração Digital. Disponível em: <http://www.receita.fazenda.gov.br/Legislacao/Decretos/2007/dec6022.htm> Acesso em: 29/mai/2009. 
Sistema público de Escrituração Digital: Percepção dos Gestores das Cooperativas Agropecuárias Catarinenses sobre os prováveis benefícios produzidos com sua implantação Carla Maria Britz, Alex Fabiano Bertolo Santana, César Augusto Lunkes

BRASÍLIA. Instrução Normativa da Receita Federal do Brasil $n^{\circ}$ 787, de 19 de novembro de 2007. Institui a Escrituração Contábil Digital. Disponível em: $<$ www.receita.fazenda.gov.br/legislacao/ins/2007/in7872007.htm> Acesso em: 28/mai/2009.

IUDÍCIBUS, Sérgio de; MARION, José Carlos. (2007). Introdução a Teoria da Contabilidade. (4 ed.). São Paulo: Atlas.

MACAPÁ-AP. Convênio ICMS n 143, de 15 de novembro de 2006. Institui a Escrituração Fiscal Digital. Disponível em: $<$ www.fazenda.gov.br/confaz/convenios/icms/2006/cv143_06.htm> Acesso em: 30/mai/2009.

MANAUS-AM. Ajuste SINIEF $n^{\circ} 7$, de 30 de setembro de 2005. Institui a Nota Fiscal Eletrônica e o Documento Auxiliar da Nota fiscal Eletrônica. Disponível em: <http://www.fazenda.gov.br/confaz/confaz/ajustes/2005/AJ_007_05.htm> Acesso em: 30/mai/2009.

MARION, José Carlos. (2004). Contabilidade Básica. (7 ed.). São Paulo: Atlas.

MINISTÉRIO DA FAZENDA. (2009). Portal Nacional da Nota Fiscal Eletrônica. Disponível em: <www.nfe.fazenda.gov.br/portal/default.aspx> Acesso em: 15/jun/2009.

NBR 5426. Planos de amostragem e procedimentos na inspeção por atributos, janeiro de 1985.

NBR 5426. Planos de amostragem e procedimentos na inspeção por atributos, janeiro de 1985.

OCESC. (2009). Listagem das Cooperativas. Disponível em <http://www.ocesc.org.br/cooperativas/enderecos.php > Acesso em: 20/jun/2009.

RECEITA FEDERAL DO BRASIL. (2009). Sitío do Sistema Público de Escrituração Digital. Disponível em: <www1.receita.fazenda.gov.br> Acesso em: 10/jun/2009.

RESENDE, Vanessa. (2008). Redução de custos e maior transparência para as empresas. Revista FENACON, Brasília, n. 127, p. 20-23, mai./jun.

SÃO PAULO. Protocolo de Cooperação ENAT $n^{\circ}$ 3, de 27 de agosto de 2005-II ENAT. Celebra a Cooperação entre a Secretaria da Receita Federal, os Estados, DF e municípios, objetivando implantar a nota fiscal eletrônica. Disponível em: http://www.nfe.fazenda.gov.br/portal/docs/legislacao_protocolo_ENAT_03.2005.pdf Acesso em: 3/jun/2009. 
Sistema público de Escrituração Digital: Percepção dos Gestores das Cooperativas Agropecuárias Catarinenses sobre os prováveis benefícios produzidos com sua implantação

Carla Maria Britz, Alex Fabiano Bertolo Santana, César Augusto Lunkes

Data de Submissão: 20/04/2010

Data de Aceite: 23/11/2010 